\title{
Quality of medical prescriptions in diabetes and hypertension management in Kerala and its associated factors
}

Vijayakumar Krishnapillai ${ }^{1,2}$, Sanjeev Nair ${ }^{1,3}$, Anand T. N1 , Sreelal T. $P^{1,2,4^{*}}$ and Biju Soman ${ }^{1,5}$

\begin{abstract}
Background: Kerala is facing challenges in the secondary prevention efforts of non-communicable diseases (NCDs). In spite of being the top performer in health parameters among Indian states, the burden of NCDs, especially diabetes mellitus (diabetes) and hypertension, is higher in Kerala. This research endeavours to identify the role of quality of medical prescriptions in secondary prevention of diabetes and hypertension and suggest corrective measures.

Methods: This cross-sectional study involved collection of prescription data and other details from consenting doctors across seven districts in Kerala. After the quality of prescription was assessed using a checklist, scores were generated, and cutoff points were used to classify the prescriptions. PASW version 18 software, was used for data analysis which included univariate and bivariate analyses and logistic regression. The proportion of quality prescriptions was estimated after adjusting for clustering, and the proportion of doctors writing quality prescriptions was also estimated. Prior to the study, ethical clearance from Independent ethics committee in Health action by People (HAP) and informed consent from all the study participants were obtained.
\end{abstract}

Results: After assessing 9199 prescriptions from 344 doctors, it was found that about 37.2\% (95\% Cl: 34.9-39.4\%) of the prescriptions were of good quality, and $48.2 \%$ (95\% Cl: 42.9-53.7\%) of the doctors provided quality prescriptions. Factors associated with quality prescriptions were found to be knowledge about NCD guidelines, quality certifications of hospitals and usage of patient data management software.

Conclusions: In the context of rising prevalence of NCDs and the challenges in the secondary prevention efforts, this is one of the first studies in Kerala to evaluate the quality of prescriptions to manage NCDs as prescriptions often reflect the quality of medical management. The study also addresses other factors associated with quality medical management. The findings indicate that the scope for improvement is more than 50\%, when considered for the overall quality of prescriptions in diabetes and hypertension management. Further, it was found that appropriate training of doctors, adherence to treatment guidelines and the use of technology may improve the overall quality of prescriptions.

Keywords: Diabetes mellitus, Hypertension, Kerala, Non-communicable diseases, Prescription, Quality

\footnotetext{
* Correspondence: tpsreelal@gmail.com

${ }^{1}$ Health Action by People, Thiruvananthapuram, Kerala, India

${ }^{2}$ Department of Community Medicine, Amrita Institute of Medical Sciences

(AIMS), Kochi, Kerala, India

Full list of author information is available at the end of the article
}

(c) The Author(s). 2020 Open Access This article is distributed under the terms of the Creative Commons Attribution 4.0 International License (http://creativecommons.org/licenses/by/4.0/), which permits unrestricted use, distribution, and reproduction in any medium, provided you give appropriate credit to the original author(s) and the source, provide a link to the Creative Commons license, and indicate if changes were made. The Creative Commons Public Domain Dedication waiver (http://creativecommons.org/publicdomain/zero/1.0/) applies to the data made available in this article, unless otherwise stated. 


\section{Background}

Kerala's health indicators are comparable to those of developed countries and [1] it is the top performing state in India in terms of health. This achievement was made possible due to its unique health system [2-4]. The health system in Kerala includes both government/ public hospitals and private hospitals. The public health system works at three levels: sub-centres and primary health centers at the primary level, community health centres and sub-district hospitals at the secondary level, and district, regional and medical college hospitals at the tertiary level. In the private sector, general practitioners and small clinics operate at the primary level, and medium and larger specialty hospitals function at the secondary and the tertiary levels. In spite of all the achievements of Kerala in the health sector, the burden of non-communicable diseases (NCDs), especially diabetes (diabetes mellitus) and hypertension, is higher here compared to other states in India. At present, medical professionals and the health care system are in an ideal position to help patients with NCDs. They are playing a crucial role in linking pharmacological and non-pharmacological methods for secondary prevention of NCDs.

Medical prescriptions play an important part in the management of non-communicable diseases. Medical prescription is a non-verbal channel which communicates medication plans from prescribers to pharmacists and patients. A good prescription should be rational, evidence based, clear, complete, and should be able to improve the treatment outcome of a patient [5]. Improper prescribing patterns include a prescription without an appropriate indication, correct dose, frequency, route of administration, schedule or duration of treatment; prescribing duplicate therapeutic agents, and medication with potential drugdrug interactions or adverse reactions are also considered to be improper pattern of prescription [6]. Prescriptions of poor quality can lead to inappropriate uses of medicines and ineffective treatment outcomes [7]. The prescription patterns of physicians are powerful tools to ascertain the role of drugs in society.

However, there is uncertainty among physicians regarding the selection of drugs because various trials are coming out with divergent results, and various guidelines reviewing the contemporary literature are arriving at different conclusions. Therefore, the secondary prevention efforts of diabetes and hypertension in the state are facing challenges which have resulted in high cardiovascular morbidity and mortality.

According to PROLIFE study conducted in Kerala, the age-standardized cardiovascular disease death rates were 490 for men and 231 for women per 100,000 person years [8]. This finding communicates the need for reassessing the secondary prevention strategies of the state.
Hence, there is a need for studying the pattern of drug prescriptions for diabetes and hypertension management, along with the assessment of subjective and objective factors that affect doctors' prescription patterns. Quality assessment of prescriptions and adherence to NCD management guidelines will help to increase prescription quality, improve the rationality of drug use, to identify the problems in secondary prevention of NCD, and take corrective actions. Therefore, our objective was to assess the quality of prescriptions offered by doctors in diabetes and hypertension management in Kerala and to find out the proportion of doctors offering quality prescriptions along with the associated factors.

\section{Methods}

This is a cross-sectional study conducted in 7 districts (Thiruvananthapuram, Kottayam, Waynad, Alappuzha, Ernakulam, Kozhikode, Kasargod) that were randomly selected from 14 districts of Kerala. Further, a sample size of 333 doctors was calculated (with 95\% confidence level, relative precision of $20 \%$ and a design effect of 1.5 ) on the assumption that $30 \%$ of doctors/physicians gave "quality prescriptions" (based on the results of a student research project conducted in the Department of Community Medicine, Medical College, Trivandrum).

Primary and secondary care level health institutions were included in the study. 182 public sector institutions from 7 districts were randomly selected from a list of 499 institutions obtained from Directorate of Health Services (DHS), Kerala. Also, 162 private clinics and hospitals were selected randomly from a list of institutions prepared from these districts. Only doctors who are specialists in managing NCDs or who are managing NCD cases more frequently were considered for the study. One consenting doctor from each institution was included in the study. Further, ethical clearance was obtained from Independent ethics committee in Health Action by People (HAP). Written informed consent was obtained from all the study participants, and prescription data collected were masked from personal identification information.

Information on doctors and institutional characteristics was collected using a questionnaire. A new tool or checklist (Additional file 1) was developed in consultation with an expert committee and by reviewing other available prescription quality tools. It contained 19 items under different quality domains - General prescription quality (3 items), Patient information quality (5 items), Pharmacological intervention quality (6 items - which included 4 items for diabetes only, 2 items for hypertension only and all 6 items for hypertension with diabetes), Lifestyle modification advice (5 items). Item scores or ratings were decided based on the priority mentioned by the expert panel. 
After these preparations a pilot study was conducted in selected private clinics and primary health centers (PHCs) in Thiruvananthapuram district and based on its observations, the data collection process was revised. Soon, trained field data collectors contacted the consenting doctors in the selected institutions and collected information using a questionnaire. The field data collectors also took photographs of prescriptions (diabetes/ hypertension/ diabetes with hypertension) given by the doctors using tablets, and digital copies of prescriptions were collected. However, identification details of patients and institutions were not collected. At least 25 prescriptions were collected from each doctor and communication was maintained with each doctor to ensure data quality. Both retrospective and prospective prescriptions were collected. All the prescriptions were \pm 6 months from the date on which consent was obtained. A Research Fellow assessed the data for any errors and a qualified pharmacist assisted in data entry from the prescriptions.

In the next stage, all prescriptions were assessed using the checklist (Additional file 1) and aggregated scores were generated for each prescription. Good/quality prescriptions were selected using the predetermined cutoff points or scores developed in consultation with experts and in comparison with previous studies. The minimum scores required for a quality prescription was 11 out of 27 (maximum score) for diabetes mellitus, 9 out of 22 in hypertension and 15 out of 33 for hypertension with diabetes mellitus cases. From each consenting doctor in the study 25 prescriptions were assessed and a doctor was considered to be providing quality prescriptions, if more than $40 \%$ prescriptions were of good quality.

Statistical analysis: Data entry and analysis were done using Epi-data version 3.1and PASW version 18 respectively. The unit of analysis was doctors. Mean and standard deviation were used to summarize continuous variables frequencies and proportions were used to summarize categorical variables. While calculating the proportion of quality prescriptions, the clustering effect was taken into account and adjusted for clustering. Bivariate analysis was done to estimate Odds ratios and 95\% confidence intervals. Logistic regression analysis was done to estimate adjusted odds ratios and confidence intervals; here dependent variable was doctors issuing quality prescriptions. The variables which were statistically significant in bivariate analysis were selected as independent variables.

\section{Results}

Prescription practice of 344 doctors was assessed based on 9199 prescriptions collected from them. Proportion of doctors issuing good quality prescriptions as well as proportion of good quality prescriptions in the study was assessed. The study found that $48.2 \% \quad(95 \%$ confidence interval (95\% CI) 42.9-53.7\%), $n=166$, of the doctors were writing good/quality prescriptions: $58.3 \%$ (95\% CI: $51.0-65.6 \%), n=102$, in the public sector and $37.9 \%$ (95\% CI: $30.6-45.2 \%), n=64$ in the private sector. A rural-urban difference was also observed: 52.3\% (95\% CI: $46.3-58.3 \%), n=139$, of doctors in rural areas gave quality prescription compared to only $34.6 \%$ (95\% CI: $24.1-45.2 \%), n=27$, in urban areas.

Looking at the details, a total of 9199 prescriptions of NCDs were collected which included prescription of hypertension $n=3373$ (36.7\%), diabetes $n=2730$ (29.7\%), and diabetes with hypertension $n=3096$ (33.7\%). The proportion (Crude) of good/quality prescriptions was $37.2 \%$ ( $n=3419)$ (95\% CI of 36.2-38.2\%); however, after adjusting for clustering, the proportion of quality prescriptions was $37.2 \%$ (95\% CI: 34.9-39.4\%) which was arrived at after standard error was calculated using adjusted analysis for clusters. When the proportion of quality prescriptions for the selected diseases was calculated it was 79.6\% (95\% CI: $78.2-80.9 \%)(n=2684)$ in hypertension, $16.8 \%(95 \% \mathrm{CI}$ : 15.4-18.3\%) $(n=460)$ in diabetes and 8.9\% (95\% CI: 7.99.9\%) $(n=275)$ in diabetes with hypertension. Other relevant findings were that diagnosis was written only in $25 \%$ prescriptions, a majority of the prescriptions contained details such as date, dose, route and timings, patient age, medications and only few prescriptions had life style modification advice namely, cessation of tobacco and alcohol consumption, weight reduction, salt restriction and increasing physical activity (Table 1 ).

Considering prescriptions which had results of basic investigations such as blood pressure and results of blood tests, it was calculated that $57.3 \%(n=5268)$ of all the prescriptions had such information. To be specific, such information was present in $70.5 \%(n=2377)$ of hypertension prescriptions, $59.4 \%(n=1839)$ of diabetes with hypertension prescriptions and $38 \%(n=1052)$ of the diabetes prescriptions. Results of blood glucose tests were mentioned in $34.5 \%(n=3178)$ prescriptions, which included FBS $(n=1387)$, PPBS $(n=526)$, RBS $(n=1175)$, HbA1C $(n=6)$. Further, blood glucose test results were mentioned in $46.2 \%(n=1262)$ diabetes prescriptions and $44.3 \%(n=1370)$ of diabetes with hypertension prescriptions, but it was low in hypertension prescriptions $16.2 \%(n=546)$. Anthropometric measurements were mentioned only in a few prescriptions [4\% $(n=365)]$ (Table 1), which included 5.3\% $(n=179)$ in hypertension, $4.2 \%(n=129)$ in Diabetes with hypertension and $2.1 \%$ $(n=57)$ in diabetes.

Regarding the use of statins, it was found that $21.8 \%$ $(n=2009)$ prescriptions had statins, and Atorvastatin was the most commonly prescribed statin, $91.2 \% \quad(n=$ 1834). However, there was no major difference in the prescription of statins with the quality of prescriptions 21.3\% $(n=727)$ in good quality prescriptions versus 
Table 1 The domains, items and findings from the prescription quality checklist. $(N=9199)$

\begin{tabular}{|c|c|c|}
\hline Domains & Items & Availability N (\%) \\
\hline \multirow[t]{3}{*}{ General prescription quality } & 1. Date of prescription & $8444(91.8)$ \\
\hline & 2. Dose, route and timings clearly mentioned & $9154(99.5)$ \\
\hline & 3. Medical Diagnosis mentioned & $2298(25.0)$ \\
\hline \multirow[t]{5}{*}{ Patient information quality } & 4. Patient Age mentioned & $8709(94.7)$ \\
\hline & 5. Patient Gender & $5157(56.1)$ \\
\hline & 6. Patient Height/Weight/BMl & $365(4.0)$ \\
\hline & 7. Patient Blood Pressure & $5268(57.3)$ \\
\hline & 8. Patient Blood sugar/HbA1c & $3178(34.5)$ \\
\hline \multirow[t]{15}{*}{ Medication/Pharmacological intervention quality } & Diabetes $(N=2730)$ & \\
\hline & 9. "Metformin" prescribed & $2103(77.0)$ \\
\hline & 10. Statins prescribed & $458(16.8)$ \\
\hline & 11. ACEI/ARB prescribed & $9(0.3)$ \\
\hline & 12. Use of more than one drug from same group & $48(1.8)$ \\
\hline & Hypertension $(N=3373)$ & \\
\hline & 13. Is patient on $24 \mathrm{~h}$ antihypertensive & $3196(94.8)$ \\
\hline & 14. ACEI/Beta Blocker/CCB/Thiazide Diuretics & $3196(94.8)$ \\
\hline & Diabetes with Hypertension 9-14 $(N=3096)$ & \\
\hline & "Metformin" prescribed & $2257(72.9)$ \\
\hline & Statins prescribed & $889(28.7)$ \\
\hline & ACEI/ARB prescribed & $1387(44.8)$ \\
\hline & Use of more than one drug from same group & $9(3.1)$ \\
\hline & Is patient on $24 \mathrm{~h}$ antihypertensive & $2887(93.2)$ \\
\hline & ACEI/Beta Blocker/CCB/Thiazide Diuretics & $2887(93.2)$ \\
\hline \multirow[t]{5}{*}{ Lifestyle modification advice/Additional Points } & 15. Tobacco cessation advice & $5(0.1)$ \\
\hline & 16. Weight reduction & $17(0.2)$ \\
\hline & 17. Alcohol consumption cessation & $6(0.1)$ \\
\hline & 18. Salt restriction & $5(0.1)$ \\
\hline & 19. Improving physical activity & $5(0.1)$ \\
\hline
\end{tabular}

$22.2 \%(n=1282)$ in poor quality prescriptions $)(p<$ $0.001)$. It is also noticeable that statins were prescribed almost equally in public [21.7\% $(n=1089)]$ and private [22.0\% $(n=920)]$ institutions, $(\mathrm{p}<0.001)$. One remarkable finding is that statins were prescribed more in case of diabetes with hypertension $28.7 \%(n=889)$ compared to diabetes, $16.8 \%(n=458)$ or hypertension, $19.6 \%(n=$ $662)$ alone, and this was statistically significant $(p<$ 0.001).

Considering the most commonly prescribed drugs, in diabetes mellitus (diabetes only or with hypertension), it was Metformin 67.8\% ( $n=3951)$, followed by Glimepiride $33.4 \%(n=1946)$ and insulin which was prescribed to $19.8 \%(n=1153)$ patients (Table 2). For patients with hypertension (hypertension alone or with diabetes mellitus), Amlodipine 50.7\% $(n=3282)$ was the most preferred antihypertensive drug, followed by Atenolol 22.0\% $(n=1426)$ (Table 3).
As regards the association between quality of prescriptions and disease control status, it was found that in patients with diabetes only, glycemic control was high in the presence of good quality prescription $47.0 \%$ compared to poor quality prescription $34.8 \%$ and this was significant $(p$-value $=0.002)$ (Tables $4 \& 5)$. On the contrary, in patients with hypertension only, the poor quality prescription group showed a higher proportion of $\mathrm{BP}$ control (38.5\%) compared to good quality prescription $30.2 \%$. However, in diabetes with hypertension group, there was no significant association between disease control status and quality of prescriptions.

In bivariate analysis, the significant factors that were associated with writing of good quality prescriptions by doctors were found to be age of the doctors, number of years of experience, number of patient consultation per day, hospital type, hospital location, awareness about NCD guidelines, quality certification and availability of 
Table 2 Drugs prescribed for diabetic patients (Diabetes and Diabetes with hypertension)

\begin{tabular}{|c|c|c|c|c|c|c|}
\hline \multirow{2}{*}{$\begin{array}{l}\text { Variables } \\
\text { Antidiabetic drugs }\end{array}$} & \multicolumn{2}{|c|}{ Diabetes $(N=2730)$} & \multicolumn{2}{|c|}{ Diabetes with Hypertension $(N=3096)$} & \multicolumn{2}{|c|}{ Total $(N=5826)$} \\
\hline & $\bar{n}$ & $\%$ & $\mathrm{n}$ & $\%$ & $\bar{N}$ & $\%$ \\
\hline Metformin & 1893 & 69.3 & 2058 & 66.5 & 3951 & 67.8 \\
\hline Glimepride & 987 & 36.2 & 959 & 31.0 & 1946 & 33.4 \\
\hline Glibenclamide & 557 & 20.4 & 795 & 25.7 & 1352 & 23.2 \\
\hline Inj Human Mixtard & 576 & 21.1 & 577 & 18.6 & 1153 & 19.8 \\
\hline Acarbose & 210 & 7.7 & 143 & 4.6 & 353 & 6.1 \\
\hline Pioglitazone & 138 & 5.1 & 54 & 1.7 & 192 & 3.3 \\
\hline Gliclazide & 63 & 2.3 & 104 & 3.4 & 167 & 2.9 \\
\hline
\end{tabular}

software for patient data management (Table 6). However, after logistic regression analysis, only quality certification of the hospitals, awareness of NCD guidelines and usage of software for patient data management was found to be the significant factors (Table 6).

Variable(s) entered in logistic regression are - age group, experience of doctor, Patient consultation per day, hospital type, hospital location, awareness of NCD guidelines, quality certification, software for patient management.

\section{Discussion}

There are two main findings of this study. Firstly, over one-third of the prescriptions for NCD management were of good quality and nearly half of the doctors gave quality prescriptions to their patients with NCDs which included diabetes, hypertension or both. Secondly, factors such as doctors 'training status, adherence to NCD guidelines, institutional quality assurance and the role of prescribing software in reducing errors in prescriptions have had a major impact on prescription quality. This has been stated elsewhere as an important component of evidence informed practice [9].

On analyzing the quality of prescriptions, the majority of the prescriptions for hypertension were found to be of good quality. This is in contrast to the study done by Suthar J and Patel V, who had used prescription quality index as a tool to measure quality of prescriptions [10].
However, in the case of diabetes with hypertension, the proportion of quality prescriptions was low. This may be attributed to the complexity of treatment, including the stages of the disease, any comorbidities and number of medications required. Only one-fourth of the prescriptions had an accurate diagnosis unlike what a few other studies had found $[11,12]$.

Metformin for diabetes mellitus and amlodipine for hypertension were the most common drugs prescribed. In the anti-diabetic prescriptions, most common oral hypoglycemic agent (OHA) prescribed was metformin (biguanide group) followed by glimipride (sulphonyl urea) as reported in other studies from South India [13-15]. A few studies in tertiary care settings in India also showed similar findings, but the proportions were low $[14,15]$. The standard guidelines recommend the use of metformin as the first choice antidiabetic for patients with type 2 diabetes mellitus [16]. Similar to other studies [15], insulin accounts for about one-fifth of the anti-diabetic prescriptions. For blood pressure (BP) management, the JNC guidelines recommend Thiazide diuretics as a first-line drug, either alone or in conjunction with other groups of antihypertensive drugs [17]. In this study, Thiazide diuretic prescription was only minimal whereas amlodipine (calcium channel blocker) was the most prescribed anti-hypertensive medication followed by atenolol (beta blocker). This

Table 3 Drugs prescribed for hypertensive patients (hypertension and diabetes with hypertension)

\begin{tabular}{|c|c|c|c|c|c|c|}
\hline \multirow{2}{*}{$\begin{array}{l}\text { Variables } \\
\text { Antihypertensives }\end{array}$} & \multicolumn{2}{|c|}{ Hypertension $(N=3373)$} & \multicolumn{2}{|c|}{ Diabetes with Hypertension $(N=3096)$} & \multicolumn{2}{|c|}{ Total $(N=6469)$} \\
\hline & $n$ & $\%$ & $n$ & $\%$ & $\mathrm{~N}$ & $\%$ \\
\hline Amlodipine & 1842 & 54.6 & 1440 & 46.5 & 3282 & 50.7 \\
\hline Atenolol & 753 & 22.3 & 673 & 21.7 & 1426 & 22.0 \\
\hline Losartan & 711 & 21.1 & 649 & 21.0 & 1360 & 21.0 \\
\hline Telmisartan & 293 & 8.7 & 477 & 15.4 & 770 & 11.9 \\
\hline Hydrochlorothiazide & 187 & 5.5 & 166 & 5.4 & 353 & 5.5 \\
\hline Enalapril & 115 & 3.4 & 154 & 5.0 & 269 & 4.2 \\
\hline Ramipril & 18 & 0.5 & 43 & 1.4 & 61 & 0.9 \\
\hline Lasix & 16 & 0.5 & 26 & 0.8 & 42 & 0.6 \\
\hline
\end{tabular}


Table 4 Comparison of Blood Pressure control status with the Quality of Prescriptions among patients with hypertension or Diabetes with hypertension

\begin{tabular}{|c|c|c|c|c|c|}
\hline \multirow[t]{2}{*}{ Disease category } & \multirow[t]{2}{*}{ BP control status } & \multicolumn{2}{|c|}{ Quality of Prescriptions } & \multirow[t]{2}{*}{ Total } & \multirow[t]{2}{*}{$p$-value* } \\
\hline & & $\begin{array}{l}\text { Good } \\
n(\%)\end{array}$ & $\begin{array}{l}\text { Poor } \\
\text { n(\%) }\end{array}$ & & \\
\hline \multirow[t]{3}{*}{ Diabetes with hypertension } & Controlled & $83(39.9)$ & $542(33.3)$ & $625(34.1)$ & 0.059 \\
\hline & Not Controlled & $125(60.1)$ & $1085(66.7)$ & $1210(65.9)$ & \\
\hline & Total & $208(100)$ & $1627(100)$ & $1835(100)$ & \\
\hline \multirow[t]{3}{*}{ Hypertension } & Controlled & $605(30.2)$ & $144(38.5)$ & 749 (31.5) & 0.002 \\
\hline & Not Controlled & $1396(69.8)$ & $230(61.5)$ & $1626(68.5)$ & \\
\hline & Total & $2001(100)$ & $374(100)$ & $2375(100)$ & \\
\hline
\end{tabular}

"Chi-square.

may be due to the presence of patients who were at various stages of the disease.

Further, though in this study only one-fifth of the prescriptions for hypertension contained statins, there are other multi-site prescription studies in India that have recorded more than 50\% statin prescription [18]. Even though many studies have shown the effect of statins on lowering of blood pressure, the present study shows that statin prescription in Kerala is lower than that found in other studies $[19,20]$.

It was found that very few prescriptions contained advice on lifestyle changes, such as advice on cessation of tobacco use and alcohol consumption, restriction of salt, increased physical activity, and weight reduction. This may be due to less attention provided to the behavior change component in therapy or may be because such advice are offered as recommendations (verbally) rather than written prescriptions. Hypertension and diabetes are closely linked to a person's lifestyle, and lifestyle modification is an important part of NCD management [21-23]. In diabetes with hypertension group, there was no significant association between the disease control and the quality of prescriptions. In only diabetes patients' glycemic control was significantly better in the presence of good quality prescriptions compared to the poor quality prescriptions.

Although there are many studies evaluating the presence of lifestyle advice during consultation, no studies could be found on the proportion of doctors who issued quality prescriptions in NCD management. In this study, the factors which were significantly associated with good prescription behavior in doctors were availability of the NCD treatment guideline in the hospital, quality certification of the hospital and use software for prescription.

Knowledge of NCD guidelines has been found to increase the likelihood of doctors prescribing good quality prescriptions. A similar study conducted in tuberculosis management also showed the same findings [24]. The study findings show that doctors in the public sector provided better quality prescriptions than doctors in the private sector, which may be due to a lack of adherence to standard guidelines in the private system. NCD guidelines issued by the state government are available in the public hospitals, but these guidelines are not available in many of the private clinics; this emphasizes the need to incorporate the private health care system in the NCD management program of the state.

Table 5 Comparison of blood glucose control status with the Quality of Prescriptions among patients with diabetes or diabetes with hypertension

\begin{tabular}{|c|c|c|c|c|c|}
\hline \multirow[t]{2}{*}{ Disease category } & \multirow{2}{*}{$\begin{array}{l}\text { Blood glucose } \\
\text { control status }\end{array}$} & \multicolumn{2}{|c|}{ Quality of Prescriptions } & \multirow{2}{*}{$\begin{array}{l}\text { Total } \\
n(\%)\end{array}$} & \multirow[t]{2}{*}{$p$-value ${ }^{*}$} \\
\hline & & $\begin{array}{l}\text { Good } \\
n(\%)\end{array}$ & $\begin{array}{l}\text { Poor } \\
\text { n(\%) }\end{array}$ & & \\
\hline \multirow[t]{3}{*}{ Diabetes with hypertension } & Controlled & $22(61.1)$ & $604(46.6)$ & $626(47.0)$ & 0.085 \\
\hline & Not Controlled & $14(38.9)$ & $692(53.4)$ & $706(53.0)$ & \\
\hline & Total & $36(100)$ & $1296(100)$ & $1332(100)$ & \\
\hline \multirow[t]{3}{*}{ Diabetes } & Controlled & $85(47.0)$ & $363(34.8)$ & $448(36.6)$ & 0.002 \\
\hline & Not Controlled & $96(53.0)$ & $681(65.2)$ & $777(63.4)$ & \\
\hline & Total & $181(100)$ & $1044(100)$ & $1225(100)$ & \\
\hline
\end{tabular}


Table 6 The factors associated with doctors issuing good/quality prescriptions ( $n=344)$

\begin{tabular}{|c|c|c|c|c|c|c|}
\hline \multirow[t]{2}{*}{ Variable } & \multirow[t]{2}{*}{ Category } & \multirow{2}{*}{$\begin{array}{l}\text { Total number of } \\
\text { doctors } \\
N=344\end{array}$} & $\begin{array}{l}\text { Doctors issuing quality } \\
\text { prescriptions }(n=166)\end{array}$ & \multirow[t]{2}{*}{ OR $(95 \% \mathrm{Cl})$} & \multirow[t]{2}{*}{$\begin{array}{l}\text { Adjusted OR } \\
(95 \% \mathrm{Cl})\end{array}$} & \multirow[t]{2}{*}{$p$-value } \\
\hline & & & n (\%) & & & \\
\hline \multirow[t]{2}{*}{ Age group (years) } & $20-40$ (yrs) & 176 & $95(54.0)$ & $1.6(1.1-2.5)$ & $1.2(0.7-2.1)$ & 0.42 \\
\hline & $41-80$ (yrs) & 168 & $71(42.3)$ & & & \\
\hline \multirow[t]{2}{*}{ Experience (years) } & $0-30$ yrs & 290 & $149(51.4)$ & $2.3(1.2-4.3)$ & $1.1(0.5-2.3)$ & 0.82 \\
\hline & $31-60$ yrs & 54 & $17(31.5)$ & & & \\
\hline \multirow[t]{2}{*}{ Patient Consultation (number/day) } & 0-80 /day & 176 & 68 (38.6) & $0.4(0.3-0.7)$ & $0.6(0.4-1.1)$ & 0.08 \\
\hline & 81-250/day & 168 & $98(58.3)$ & & & \\
\hline \multirow[t]{2}{*}{ Hospital type } & Public & 175 & $102(58.3)$ & $2.3(1.5-3.5)$ & $1.6(0.9-3.0)$ & 0.11 \\
\hline & Private & 169 & $64(37.9)$ & & & \\
\hline Hospital Location & Rural & 266 & $139(52.3)$ & $2.1(1.2-3.5)$ & $1.8(0.9-3.4)$ & 0.056 \\
\hline \multirow[t]{2}{*}{ Awareness on NCD guide } & Yes & 218 & $118(54.1)$ & $1.9(1.2-3.0)$ & $1.8(1.04-2.9)$ & 0.03 \\
\hline & No & 126 & $48(38.1)$ & & & \\
\hline \multirow[t]{2}{*}{ Quality certification } & Yes & 51 & $33(64.7)$ & $2.2(1.2-4.1)$ & $2.2(1.1-4.4)$ & 0.02 \\
\hline & No & 293 & $133(45.4)$ & & & \\
\hline \multirow[t]{2}{*}{ Software for patient data management } & Yes & 26 & $22(84.6)$ & $6.6(2.2-19.7)$ & $12.1(3.8-38.5)$ & $<0.001$ \\
\hline & No & 318 & $144(45.3)$ & & & \\
\hline \multirow[t]{2}{*}{ Gender } & Male & 203 & $91(44.8)$ & $0.7(0.5-1.1)$ & - & - \\
\hline & Female & 141 & $75(53.2)$ & & & \\
\hline \multirow[t]{2}{*}{ Marital status } & Married & 313 & $149(47.6)$ & $0.7(0.4-1.6)$ & - & - \\
\hline & Single & 31 & $17(54.8)$ & & & \\
\hline \multirow[t]{2}{*}{ Education } & $P G$ & 167 & $73(43.7)$ & $0.7(0.5-1.1)$ & - & - \\
\hline & MBBS & 177 & $93(52.5)$ & & & \\
\hline \multirow[t]{2}{*}{ Place of education } & Domestic & 336 & $161(47.9)$ & $0.6(0.1-2.3)$ & - & - \\
\hline & International & 8 & $5(62.5)$ & & & \\
\hline \multirow[t]{2}{*}{ Number of CMEs attended } & One CME & 236 & $118(50)$ & $1.3(0.8-1.9)$ & - & - \\
\hline & No CME & 108 & $48(44.4)$ & & & \\
\hline \multirow[t]{2}{*}{ Journal Subscription } & Yes & 96 & $47(49.0)$ & $1.0(0.6-1.7)$ & - & - \\
\hline & No & 248 & $119(48.0)$ & & & \\
\hline \multirow[t]{2}{*}{ Consultation time (hrs)/day } & $0-6 \mathrm{~h}$ & 168 & $76(45.2)$ & $0.8(0.5-1.2)$ & - & - \\
\hline & $7-11 \mathrm{~h}$ & 176 & $90(51.1)$ & & & \\
\hline \multirow[t]{2}{*}{ Contract Type } & Permanent & 269 & $136(50.6)$ & $1.5(0.9-2.6)$ & - & - \\
\hline & Temporary & 75 & $30(40.0)$ & & & \\
\hline \multirow[t]{3}{*}{ Clinical research } & Yes & 39 & $20(51.3)$ & $1.1(0.6-2.2)$ & - & - \\
\hline & No & 305 & $146(47.9)$ & & & \\
\hline & Urban & 78 & $27(34.6)$ & & & \\
\hline \multirow[t]{2}{*}{ Pharmacy availability } & Yes & 327 & $159(48.6)$ & $1.4(0.5-3.6)$ & - & - \\
\hline & No & 17 & $7(41.2)$ & & & \\
\hline
\end{tabular}

Likewise, doctors tend to provide more quality prescriptions for NCDs in institutions with a quality assessment system. Previous studies also indicate that enhancing the competence of doctors, strengthening adherence to guidelines and performance evaluation [25] would improve quality prescribing behavior. In this study, usage of software for prescription was also associated with good prescription pattern.

Many studies have also shown that use of electronic prescribing systems in hospitals can help to reduce prescription errors. This may improve the quality of prescriptions as well as quality of care [26, 27], but this 
requires sufficient funding and extensive training of doctors on the usage of electronic system.

Factors such as age of doctors, years of experience, number of patients consulted per day, location of hospitals, and type of hospitals showed no significant association after adjusting for the confounders. Some studies have shown a positive association between uptake of a newer drug and doctor's age, but there is no relevant study stating the association with quality of prescription in NCD management [25]. A systematic review has shown that doctors with more clinical experience may be at risk of non-compliance with standards of care for therapy and thus may provide poor quality care [28]. Similar results have been found in this study, with doctors with fewer years of experience giving more quality prescription. The reason may be that they are updated on latest guidelines and are willing to adopt newer drugs. Doctors who consult more patients are associated with quality prescription behavior; this indicates that patients meet doctors who give quality care. Doctors who participate in continuing medical education, frequently read scientific journals and have experience in clinical research provided quality prescriptions compared to their counterparts who did not engage in these activities. However, these results were not found to be statistically significant in this study, which could be due to a lack of adequate sample size.

There were some limitations of the study. A significant one was that the prescription quality was assessed using a checklist developed solely based on expert consultation, and the patient side data were not collected. The findings were therefore less representative of the factors associated with the patients. Another major limitation was that there is a potential chance of bias from some participating doctors altering their prescribing behavior, consequent to an awareness of being part of the study, but this bias may be minimal since we have some retrospective as well as prospective prescription data. Moreover, some lifestyle modification advice might have been given verbally, and that part is lacking in the prescription analysis. Finally, the sample size was estimated to capture the proportion of doctors issuing good quality prescriptions, so the sample may not be adequate to identify the factors associated.

\section{Conclusion}

With heavy burden of non-communicable diseases and its complications, Kerala is facing serious problems in the secondary prevention efforts of diabetes and hypertension. As medical prescriptions are an important part of medical management of NCDs,periodic quality assessment, corrections based on the findings of the assessment and adherence to medical management guidelines will help to improve the rationality of drug use, to identify issues related to secondary prevention of NCDs, and to take corrective actions.

This is one of the first studies to evaluate the quality of prescriptions in diabetes mellitus and hypertension management in Kerala. Prescriptions from both public and private care providers were subjected to quality assessment. The findings show the need to improve the quality of prescriptions issued by doctors. The policy implications are the following: There is a need to periodically publish guidelines for diabetes mellitus and hypertension management and provide to doctors in both public and private sectors. The training for doctors should be extended to both public and private sectors. The modern technology such as electronic prescribing systems should be used to reduce prescription errors and to improve quality of care. Similarly, continuous monitoring of the quality and adequate corrections on guidelines are essential for improving the medical management.

\section{Supplementary information}

Supplementary information accompanies this paper at https://doi.org/10. 1186/s12889-020-8214-y.

Additional file 1. PRESCRIPTION QUALITY ASSESSMENT CHECKLIST.

\section{Abbreviations \\ BP: Blood pressure; CME: Continuing Medical Education; DHS: Directorate of Health Services; FBS: Fasting Blood Sugar; HAP: Health action by People; ICMR: Indian Council of Medical Research; JNC: Joint National Committee on Hypertension; LSM: Lifestyle modification; NCD: Non-communicable disease; OHA: Oral hypoglycemic agent; PASW: Predictive Analytics SoftWare; \\ PHC: Primary health centers; PPBS: Post Prandial Blood Sugar; \\ PROLIFE: Population Registry of Lifestyle Diseases; RBS: Routine Blood Sugar}

\section{Acknowledgments}

We would like to express our sincere gratitude towards ICMR (IndianCouncil for Medical Research) for funding and supporting this research project (No. 5/4/1-21/12-NCD-II).

\section{Authors' contributions}

VK, SN and BS conceptualized and designed the study. VK, ATN and STP were involved in the data acquisition and takes responsibility for the data integrity. STP, ATN and VK were involved in the data analysis and interpretation of the results. STP, ATN and VK drafted the first version of the manuscript and was reviewed by SN and BS. STP, ATN and VK made revisions to the manuscript. All authors have read and approved the manuscript.

\section{Funding}

This study was funded by the Indian Council of Medical Research (ICMR); grant number is No. 5/4/1-21/12-NCD-II.

\section{Availability of data and materials}

The data sets used and/or analyzed during the current study are available from the corresponding author on reasonable request.

\section{Ethics approval and consent to participate}

Ethical clearance (IEC.No EC I/JUNE/2014/HAP) obtained from Independent ethics committee in Health action by People (HAP). Written informed consent from all the study participants was obtained, and prescription data collected were masked from personal identification information. 


\section{Consent for publication}

Not applicable.

\section{Competing interests}

The authors declare that they have no competing interests.

\section{Author details}

${ }^{1}$ Health Action by People, Thiruvananthapuram, Kerala, India. ${ }^{2}$ Department of Community Medicine, Amrita Institute of Medical Sciences (AIMS), Kochi, Kerala, India. ${ }^{3}$ Department of Pulmonary Medicine, Government Medical College, Thiruvananthapuram, India. ${ }^{4}$ International Decision Support Initiative (iDSI), London, UK. ${ }^{5}$ Achutha Menon Centre for Health Science Studies (AMCHSS), SCTIMST, Thiruvananthapuram, India.

Received: 27 November 2018 Accepted: 14 January 2020

Published online: 06 February 2020

\section{References}

1. Health NF. India [Internet]. 2015. Available from: http://rchiips.org/NFHS/ NFHS-4Reports/India.pdf

2. Ministry of Health \& Family Wefare. Healthy States, Progressive India:Report on the Ranks of S tates and Union Territ ories. Moh\&Fw, Niti Ayog, World Bank [Internet]. 2017; Available from: http://social.niti.gov.in/

3. UNDP. Human Development Report Kerala 2005. 2006; Available from: http://www.in.undp.org/content/india/en/home/library/hdr/humandevelopment-reports/State_Human_Development_Reports/Kerala.html

4. Nadu T. Positive outlier: Health outcomes in Kerala, India over time. 2018; Available from: https://www.globalhealthdelivery.org/files/ghd/files/ghd042_kerala_as_a_positive_outlier_2018_09_05.pdf

5. Joshi A, Buch J, Kothari N, Shah N. Evaluation of hand written and computerized out-patient prescriptions in urban part of Central Gujarat. J Clin Diagnostic Res. 2016;10(6):FC01-5.

6. Hassan N, Ismail SB, Noor SH. Doctor-shopping behaviour amongst adult patients attending family medicine clinic, Hospital Universiti Sains Malaysia, Kubang Kerian, Kelantan. Int Med J Tokyo. 2005;12(4):251.

7. Hogerzeil $\mathrm{H}$. Promoting rational prescribing: an international perspective. Br J Clin Pharmacol. 1995;39(1):1-6.

8. Soman CR, Kutty VR, Safraj S, Vijayakumar K, Rajamohanan K, Ajayan K, et al. All-cause mortality and cardiovascular mortality in Kerala state of India: results from a 5-year follow-up of 161942 rural community dwelling adults. Asia Pacific J public heal [internet]. 2011;23(6):896-903 Available from: https://doi.org/10.1177/1010539510365100.

9. Hassan NB, Ismail HC, Naing L, Conroy RM, Abdul Rahman AR. Development and validation of a new prescription quality index. $\mathrm{Br} J$ Clin Pharmacol. 2010;70(4):500-13.

10. Suthar J, Patel V. Prescribing quality in patients with chronic diseases at primary and secondary health care facilities using prescription quality index tool. Int J Basic Clin Pharmacol [Internet]. 2014;3(3):553 Available from: http://www.ijbcp.com/?mno=158198.

11. Abdellah AE, Abdelrahman SMK. Prescription writing quality in paediatric teaching hospitals in Khartoum. Sudan J Paediatr [Internet]. 2012;12(1):64-9 Available from: http://www.sudanjp.org.

12. Shikha Mlshra PS. Prescription audit and drug utilization pattern in a tertiary care teaching hospital in Bhopal. IJBCP Int J Basic Clin Pharmacol Res Artic. 2016;5(5):1845-9.

13. Sultana S, Hamid K, Islam KMS, Roy S, Saha MR, Zulfiker AH, et al. Assessment of prescription pattern of hypertensive patients' prescription: a prescription survey study from various hospitals of Bangladesh. Eur J Sci Res [Internet]. 2010;40(4):500-5 Available from: http://doczine.com/bigdata/2/13 83754339_2ea0ad7b52/60b7d5156bcfc24bb9.pdf.

14. Agarwal AA, Jadhav PR, Deshmukh YA. Prescribing pattern and efficacy of anti-diabetic drugs in maintaining optimal glycemic levels in diabetic patients. J basic Clin Pharm [Internet]. 2014;5(3):79-83. Available from: https://www.ncbi.nlm.nih.gov/pubmed/25278671. https://www.ncbi.nlm.nih. gov/pubmed/25278671.

15. Shah K, Solanki N, Rana D, Acharya K. Evaluation of antidiabetic prescriptions, cost and adherence to treatment guidelines: A prospective, cross-sectional study at a tertiary care teaching hospital. J Basic Clin Pharm [Internet]. 2013;4(4):82 Available from: http://www.jbclinpharm.org/text.asp?2 013/4/4/82/121653.
16. Aschner P, Adler A, Bailey C, Chan JC, ChB M, Colagiuri S, et al. IDF Clinical Practice Recommendations for managing Type 2 Diabetes in Primary Care [Internet]. International Diabetes Federation. 2017. 1-36 p. Available from: https://www.idf.org/e-library/guidelines/128-idf-clinical-practicerecommendations-for-managing-type-2-diabetes-in-primary-care.html

17. Seventh Report of the Joint National Committee on Prevention, Detection, Evaluation, and Treatment of High Blood Pressure (JNC7) [Internet]. NIH Publication. 2004. Available from: https://www.nhlbi.nih.gov/health-topics/ seventh-report-of-joint-national-committee-on-prevention-detectionevaluation-and-treatment-high-blood-pressure

18. Gupta R, Lodha S, Sharma KK, Sharma SK, Gupta S, Asirvatham AJ, et al. Evaluation of statin prescriptions in type 2 diabetes: India heart watch-2. BMJ Open Diabetes Res Care. 2016;4(1):1-8.

19. Stone NJ, Robinson JG, Lichtenstein AH, Bairey Merz CN, Blum CB, Eckel RH, et al. 2013 ACC/AHA guideline on the treatment of blood cholesterol to reduce atherosclerotic cardiovascular risk in adults: a report of the American college of cardiology/American heart association task force on practice guidelines. J am Coll Cardiol. 2014;63(25 PART B):2889-934.

20. Morgado M, Rolo S, Macedo AF, Castelo-Branco M. Association of statin therapy with blood pressure control in hypertensive hypercholesterolemic outpatients in clinical practice. J Cardiovasc Dis Res [Internet]. 2011 [cited 2018 Feb 26];2(1):44-49. Available from: https://www.sciencedirect.com/ science/article/pii/S0975358311210076

21. Organization $\mathrm{WH}$. The protocol for the $\mathrm{WHO}$ study on the effectiveness of community-based programmes for NCD prevention and control. 2003; Available from: https://apps.who.int/iris/bitstream/handle/10665/68766/ a85150.pdf

22. Habib SH, Saha S. Burden of non-communicable disease: Global overview. Diabetes Metab Syndr Clin Res Rev [Internet]. 2010[cited 2019 Sep 2];4(1): 41-47. Available from: https://www.sciencedirect.com/science/article/abs/ pii/S1871402108000489

23. Zwar N, Harris M, Griffiths R, Roland M, Dennis S, Powell Davies G HIA. A systematic review of chronic disease management. Research Centre for Primary Health Care and Equity, School of Public Health and Community Medicine, UNSW. 2006.

24. Greaves F, Ouyang H, Pefole M, MacCarthy S, Cash RA. Compliance with DOTS diagnosis and treatment recommendations by private practitioners in Kerala. India Int J Tuberc Lung Dis. 2007;11(1):110-2.

25. Wang H, Li NN, Zhu H, Xu S, Lu H, Feng ZC. Prescription Pattern and Its Influencing Factors in Chinese County Hospitals: A Retrospective CrossSectional Study. PLoS One. 2013;8(5). https://doi.org/10.1371/journal.pone. 0063225

26. Hitti E, Tamim H, Bakhti R, Zebian D, Mufarrij A. Impact of internally developed electronic prescription on prescribing errors at discharge from the emergency department. West J Emerg Med. 2017;18(5):943-50.

27. Imambaccus N, Glace S, Heath R. Increasing the uptake of electronic prescribing in primary care. 2017; Available from: http://bmjopenquality.bmj. com/content/bmjqir/6/1/u212185.w4870.full.pdf

28. Choudhry NK, Fletcher RH, Soumerai SB. Improving patient care systematic review : the relationship between clinical experience and quality of Health care. Am Coll Physicians. 2005;142:260-73.

\section{Publisher's Note}

Springer Nature remains neutral with regard to jurisdictional claims in published maps and institutional affiliations.

Ready to submit your research? Choose BMC and benefit from:

- fast, convenient online submission

- thorough peer review by experienced researchers in your field

- rapid publication on acceptance

- support for research data, including large and complex data types

- gold Open Access which fosters wider collaboration and increased citations

- maximum visibility for your research: over $100 \mathrm{M}$ website views per year

At BMC, research is always in progress.

Learn more biomedcentral.com/submissions 